$\S=-1$

\title{
Modelling of Solar Spectral Radiation in Penang Island on a Digital Elevation Model
}

\author{
EngChoon Yeap ${ }^{1}$, HweeSan $\operatorname{Lim}^{2} *$, Zubir MatJafri ${ }^{3}$ \\ School of Physic, 11800 Universiti Sains Malaysia, Penang, Malaysia \\ *Corresponding author E-mail: hslim@usm.my
}

\begin{abstract}
Interest has been increasingly focused on the studies of solar radiation across the globe ever since people are more concern about energy conservation. Due to the increment of terrestrial application of solar energy, the scientific interest on solar distribution has expanded from broadband solar energy to its spectral distribution. Measurement of solar radiation with its spectral profile provides knowledge for making important decisions involving resources and energy, agriculture and climate. In remote sensing, the measurement of spectral solar radiation is important for sensor calibration and image enhancement to extract the most information out of a satellite image. The spectral radiation can be measured using spectral radiometer specifically design for measuring solar radiation; however such instruments are expensive and only provide point data which is very limited in most studies. This study aims to provide a rigorous spectral radiation model that predict the spectral solar irradiance in temporal resolution of every minute with spectral range from $350 \mathrm{~nm}$ to $2200 \mathrm{~nm}$ under cloudless condition. The parameters used in this model include the distance between sun and earth, time, coordinate, atmospheric interference and terrain effect. Atmospheric sounding data was used in this study to provide the necessary atmospheric parameter in the si mulation of solar propagation through the atmosphere. The atmospheric effects considered in this study include Rayleigh scattering, aerosol attenuation and the absorption of water vapor, ozone and uniformly mixed gas. The simulation results were projected onto a digital elevation model to further calculate the effect introduced by the topographic variation and to get a three dimensional solar spectral radiation. The result obtained from this study is compared with spectral solar irradiance data collected during the month of June and July, 2018 with root mean square deviation of 9 watt per meter square at the wavelength of $350 \mathrm{~nm}$ to $2200 \mathrm{~nm}$.
\end{abstract}

Keywords: Atmospheric Model; Atmospheric Transmission; Radiative Transfer Model; Solar irradiance; Solar Simulation.

\section{Introduction}

Our Sun emitted solar radiation that is close to a black body at temperature near 5800K (Vasarevicius and Martavicius, 2011). The solar radiation covers the entire electromagnetic spectrum from gamma rays, X-rays, ultraviolet, visible, infrared, microwaves and radio waves. According to Eltbaaks(2011), a total of 99 percent of solar energy reaching the Earth falls between $150 \mathrm{~nm}$ and $4000 \mathrm{~nm}$.

Solar irradiance continuously generated by the sun in waveform dispersed into the space and it is assume that no energy was lost in space. At the top of atmosphere, the solar constant at one astronomical Unit $(149,597,870 \mathrm{~km})$ is around $1360.8 \mathrm{Wm}-2$ with minor variation due to the elliptical orbit of the Earth to the Sun and solar activities (Kopp and Lean, 2011; Coddington et al., 2016 ). The studies of spectral solar irradiance is important and needed by variety of applications from different disciplines. In health industries, solar irradiance at the wavelength of ultraviolet was studied in related to skin cancer (Cadet and Douki, 2018). In remote sensing, solar irradiance was used in radiometric calibration of remote sensed imageries to improve image quality and to extract the most information out of remote sensed data (Liew et al., 2017). In energy industries, solar irradiance at wavelength $300 \mathrm{~nm}$ to $1200 \mathrm{~nm}$ was used to test the spectral response of various photovoltaic element (Murshed et al., 2018). In agriculture, the photosynthetically active radiation (PAR) can be related to biomass growth and near infrared reflection from vegetation can be used to identify the water stress level in the plant (Chakwizira et al., 2018).

Solar irradiance was selectively absorbed and scattered by the atmosphere during the propagation from the top of the atmosphere to the ground (Lampel et al., 2017). Primary particles that are responsible for the atmospheric effect are dust, ozone, carbon dioxide, oxygen, nitrogen dioxide, water and methane. The amount of scattering and absorption depend on the concentration of the particle in the atmosphere. A good estimation of solar irradiance on the Earth surface requires both atmospheric and geometric inputs. These parameters are usually made available through in-situ measurement, satellite measurement, meteorological station or static atmospheric models.

Solar radiation is usually measured as broadband, spectral or monochromatic. Solar radiation network (SolRad-Net) is one of the global scale solar flux monitoring network that provide quasireal-time measurement to scientific community. Some other measurements of different wavelengths are also available in many researches. Islam et al., (2009) measured solar radiation with a pyroheliometer in Abu Dhabi during 2007. His measurement provides daily and monthly solar radiation data to serve other solar related researches in that country. In 2011, solar irradiance was measured in Bangi, Malaysia using filters to achieve spectral measurement with lower cost (Eltbaakh et al., 2013). In his studies, the results were compared with a simulated software with a great accuracy. Instrument for measuring solar irradiance can be fairly expensive and only capable to provide measurement in a single location. To compensate the limited data, simulation can be 
one of the option to reduce the cost while providing a wide coverage of data.

This study aims to simulate spectral solar irradiance in Penang Island using local atmospheric sounding data, radiative transfer model and digital elevation model. This model is able to simulate the solar illumination with high spectral resolution at any instant of time based on the $\mathrm{c}$ atmospheric input.

\section{Method}

\subsection{Atmospheric Model}

When solar radiation travel through the Earth's atmosphere, the radiation was absorbed and scattered according to the atmospheric condition and path length of solar radiation, also describe as air mass (Eltbaaks et al., 2011). This changes the spectral distribution of the radiation. The spectral distribution of solar radiation reaches the Earth's surface at any given time.

Atmospheric model was used in this study to account the effect of the atmospheric effect onto solar radiation. The parameter was acquired from nearby atmospheric sounding. Yearly average atmospheric profile from Penang International Airport (WMKP) at the year 2017 was used to provide the necessary atmospheric parameters to simulate the propagation of solar irradiance. The parameter included in the atmospheric profile are atmospheric pressure, height, temperature, relative humidity and water mixing ratio from mean sea level up to $32 \mathrm{~km}$.

From the atmospheric profile, vertical water column was calculated using equation (1). The vertical water column is the total precipitable water vapour in centimetres. It is the total thickness of all water in a column of atmosphere if it were condensed at the surface. The vertical water column is needed to calculate the transmission of solar irradiance through the atmosphere caused by the water vapour.

$t w c=1000 \times \int\left(w m r(h) * \rho(h)^{-1 / 3}\right) d h$

where $t w c$, total water column; $w m r(h)$, water mixing ratio; $\rho(h)$ is the air density at height $h$. The air density was calculated using ideal gas law in equation (2)

$\rho(h)=P_{h}\left(R_{d} T_{h}\right)^{-1}$

where $P_{h}$, pressure; $R_{d}$, gas constant (287.058 J kg-1 K-1); and $T_{h}$, temperature as a function of height.

\subsection{Simulation of terrain illumination}

Solar illumination on Earth's surface is inconsistence especially at the hilly areas. The slope and aspect of the terrain change the solar incident angle on the Earth's surface. Direct solar irradiance was heavily influence by the solar incident angle while diffuse irradiance affect by the slope gradient. The calculation of the incident angle can be done with the known solar direction and digital elevation model. Digital elevation Model of Penang Island from Alos Palsar with resolution of $12.5 \mathrm{~m}$ was used in this study. The DEM was smoothen using low pass filter to reduce artefact in the data. The DEM was then converted into slope and aspect to calculate for solar incident angle $(\theta)$ using equation (3). The parameter used in equation (3) are described in figure (1) where the solar incident angle is the function of solar position, slope and aspect of the terrain.

$\cos \theta=1-\frac{\left(\sin \psi_{0}-\sin \psi_{1}\right)^{2}}{2}-\frac{\left(\cos \psi_{0}{ }^{2}+\cos \psi_{1}{ }^{2}\right)}{2}$
$+\left(\cos \psi_{0} \times \cos \psi_{1} \times \cos \left(\varphi_{0}-\varphi_{1}\right)\right)$

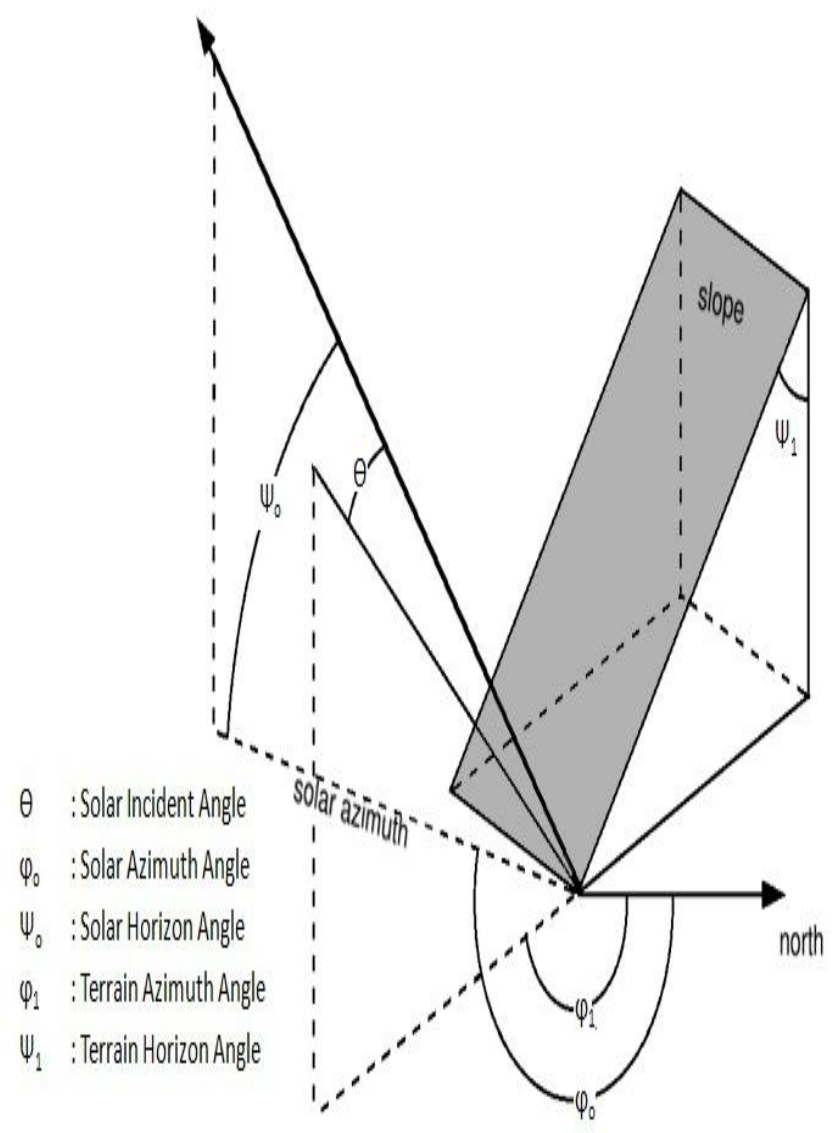

Fig. 1: Parameter involved in calculation of solar incident angle

\subsection{Simulation of solar irradiance}

To generalize the sloping surface predictions, we simplify the formulation of solar irradiance and rewrite the total solar irradiance on a sloping as

$I_{t}=\left(\cos \theta \cdot \int I_{r}(\lambda) d \lambda\right)+\left(\sin \psi \cdot \int I_{f}(\lambda) d \lambda\right)$

where $I_{t}$, total irradiance reaches the Earth surface; $\theta$, incident angle; $\psi$, slope gradient; $I_{r}$, direct irradiance and $I_{f}$, diffuse irradiance on horizontal surface.

The first term in the equation (4) describes the calculation of direct irradiance with the cosine law. Direct irradiance $\operatorname{Ir}(\lambda)$ is described in equation (5)

$I_{r}(\lambda)=I_{o n \lambda} T_{r \lambda} T_{a \lambda} T_{w \lambda} T_{o \lambda} T_{u \lambda} T_{n \lambda}$

where $I_{\text {on }}$, corrected extraterrestrial irradiance for actual EarthSun distance; $T_{r \lambda}$, Rayleigh scattering, $T_{a \lambda}$, aerosol attenuation; and $T_{w \lambda}, T_{o \lambda}, T_{u \lambda}$ are water vapour, ozone and uniformly mixed gas absorption as a function of wavelength.

The second term of equation (4) describes the calculation of diffuse irradiance $I_{f}(\lambda)$ which assumes that the diffuse irradiance was from the isotropic skies. Diffused irradiance was calculated using equation (6)

$I_{r}(\lambda)=I_{r \lambda}+I_{a \lambda}+I_{g \lambda}$

where it is generally divided into three components which are $I_{r} \lambda$, Rayleigh scattering component; $I_{a} \lambda$, aerosol scattering component; and $I_{g} \lambda$, the component that accounts for multiple reflection of irradiance between the ground and the air. This model assumes that Rayleigh and aerosol scattering are independent to each other. 


\section{Results}

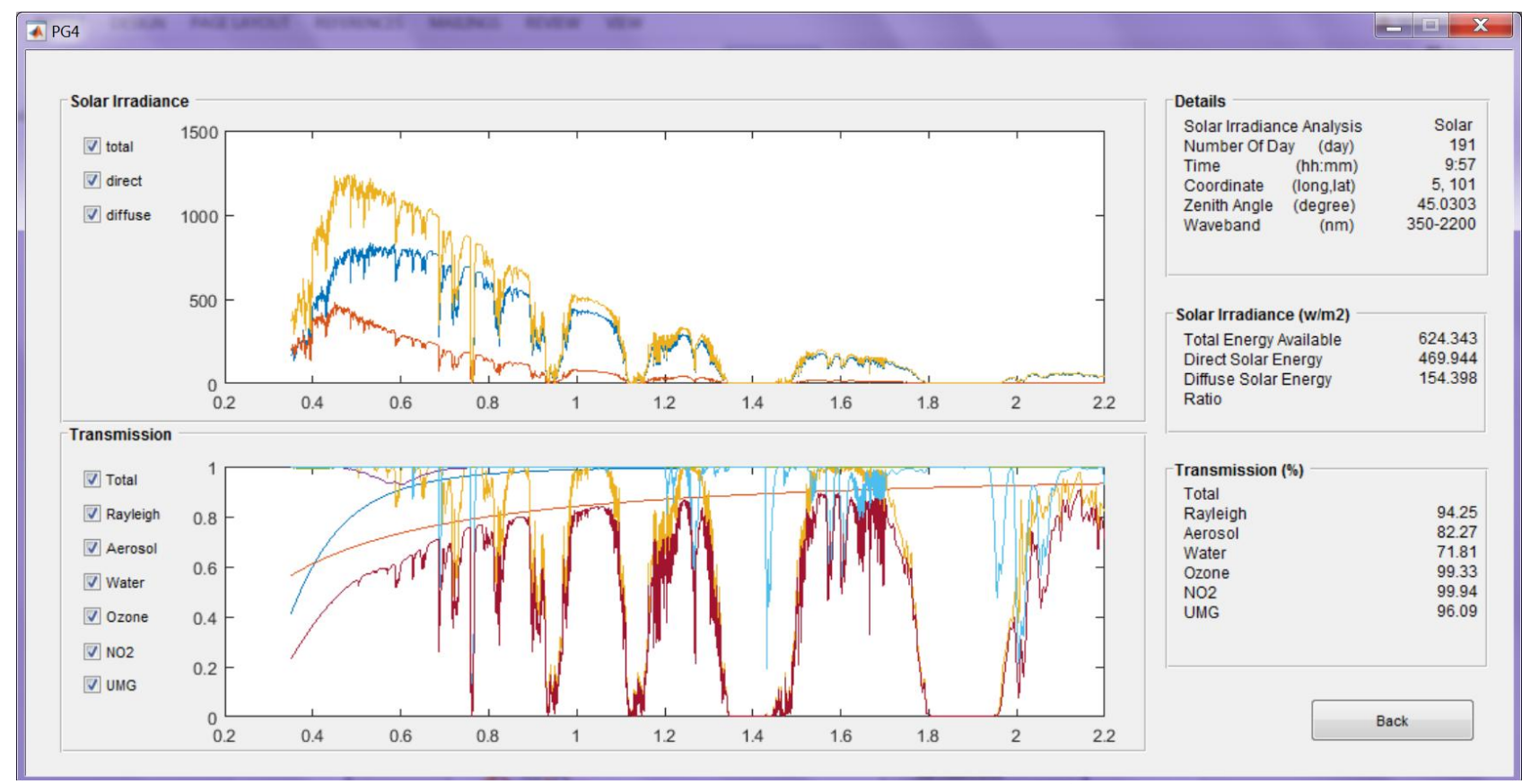

Fig. 2: Result of radiative transfer model at zenith angle of $45^{\circ}$.

This study aim to simulate the solar irradiance at surface level with high spectral resolution for any given time. The simulation is able to simulate direct and diffuse independently which allow researcher to understand more on the solar irradiance.

The simulated spectral solar irradiance from equation (3) was shown in figure (2). This result were simulated at $45^{\circ}$ zenith and $135^{\circ}$ azimuth. In this simulation, the estimated solar irradiance between $350 \mathrm{~nm}$ to $2200 \mathrm{~nm}$ is $654 \mathrm{w} / \mathrm{m}^{2}$, with $75 \%$ contributed by direct solar irradiance and $25 \%$ by diffuse solar irradiance

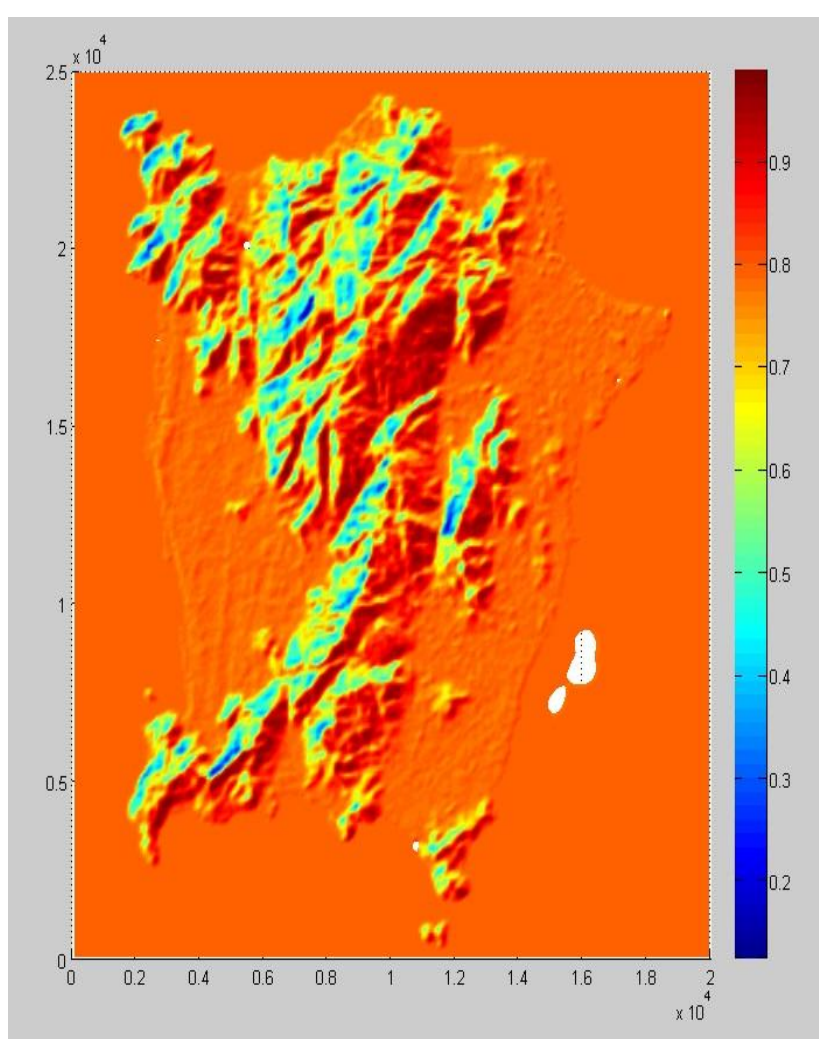

Fig. 3: Three dimensional solar illumination of Penang Island at zenith $45^{\circ}$ and azimuth $135^{\circ}$.
This result was applied on the digital elevation model to simulate three dimensional solar illumination as shown in figure (3) and (4) A total of 60 measured solar spectral data was recorded during the month of June and July, 2018. The data was acquired using solar spectrometer with effective wavelength of $350 \mathrm{~nm}$ to $2200 \mathrm{~nm}$. These data was compared with the 60 simulation results with different solar position. The overall comparison results was shown in figure 5. The simulated result was statistically tested with root mean square deviation of $9.2 \mathrm{Wm}-2$ from total irradiance.

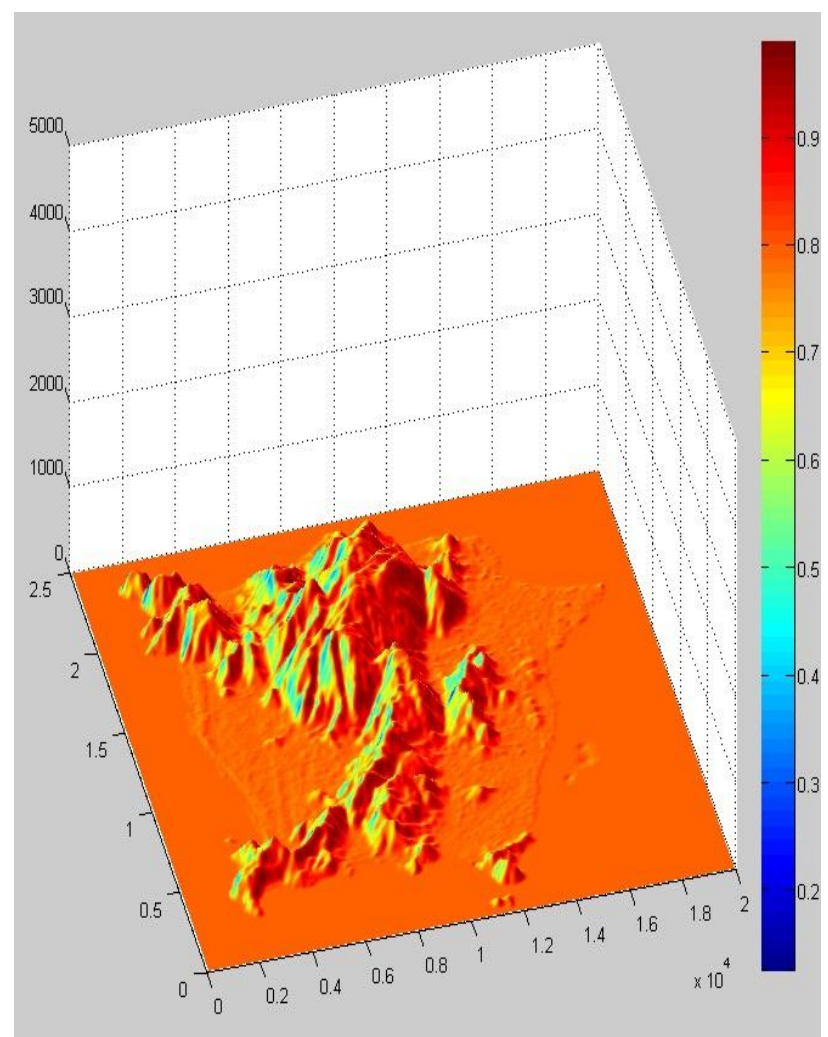

Fig. 4: Three dimensional solar illumination of Penang Island at zenith $45^{\circ}$ and azimuth $135^{\circ}$ in another angle 


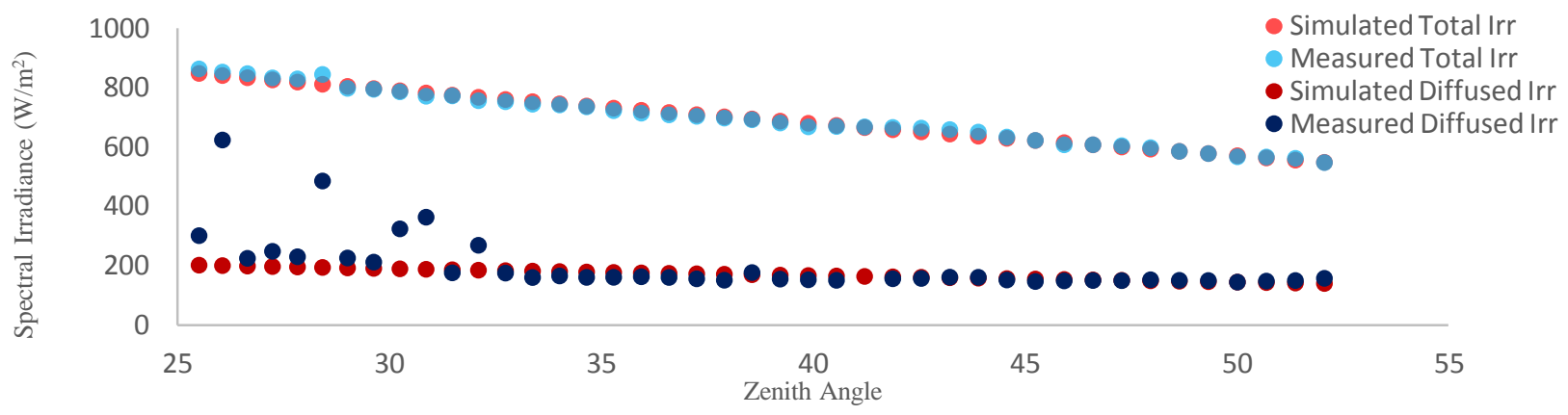

Fig. 5: The measured and simulated total/diffuse solar irradiance at the wavelength of $350 \mathrm{~nm}$ to $2200 \mathrm{~nm}$.

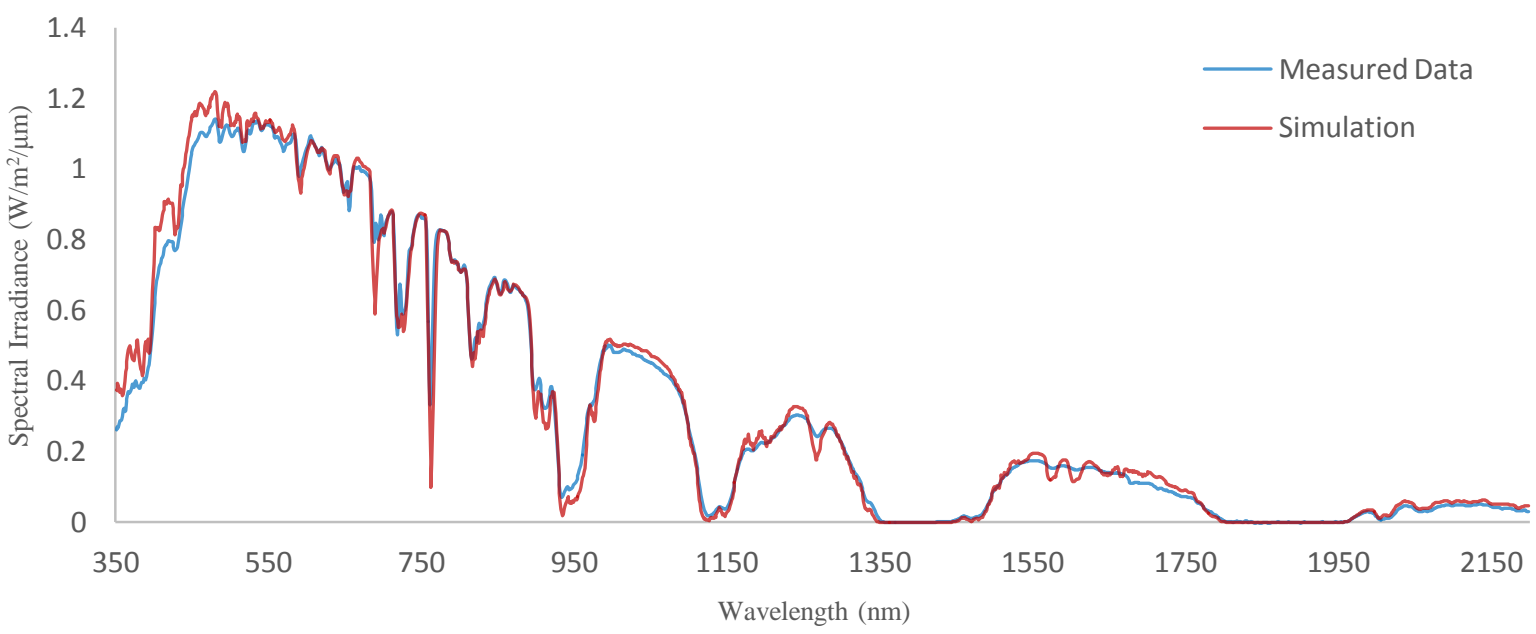

Fig. 6: Spectral comparison between simulation and measured data at $45^{\circ}$ zenith

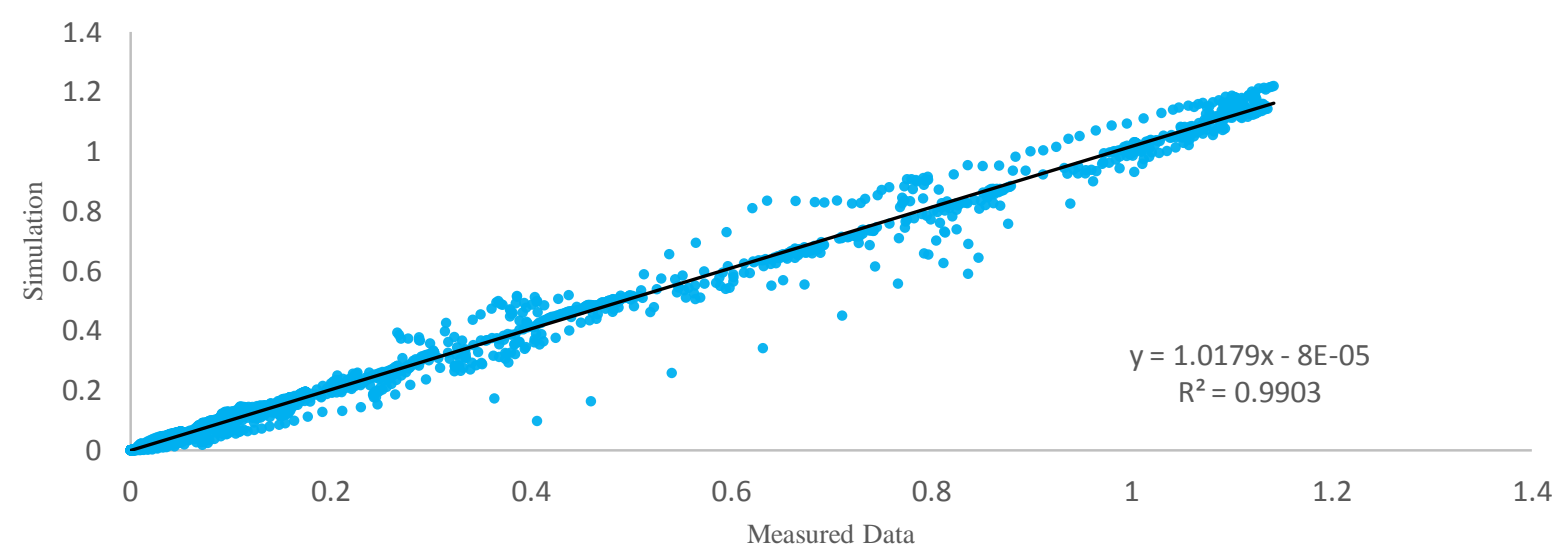

Fig. 7: Regression of broadband simulation versus measured data at $45^{\circ}$ zenith angle.

From figure 6, major water vapour absorption occurred at the wavelength $950 \mathrm{~nm}, 1150 \mathrm{~nm}, 1450 \mathrm{~nm}$ and $1850 \mathrm{~nm}$. These wavelength are especially useful in understanding water content in the atmosphere. For detailed spectral assessment, we have compared the measured total irradiance with the simulation from $25^{\circ}$ to $50^{\circ}$ zenith angle. A $7 \mathrm{~nm}$ low pass filter was applied on the simulation results to match the smoothen reading from the instrument. The coefficient of determination value for the simulation lies between 0.98 (zenith $25^{\circ}$ ) to 0.99 (zenith $50^{\circ}$ ) while root mean squared deviation is between 0.03 to $0.07 \mathrm{Wm}^{-2} \mathrm{~nm}^{-1}$ at the interested wavelength. The comparison was shown in Figure 6 and 7. In figure 6 , the simulated and measured result at $45^{\circ}$ zenith was compared. The results was statistically evaluate in figure 7 where the coefficient of determination value is 0.99 .

\section{Conclusion}

The knowledge of spectral solar irradiance on the Earth's surface is important in many fields yet the availability of spectral solar data is very limited. The results in this paper have shown that simulation of spectral solar irradiance can achieve a very high confident level under cloudless condition. Instead of point data, this simulation process allows us to simulate high spectral solar irradiance in 3 dimensional space which was previously impossible using any measurement tools. 


\section{Acknowledgement}

This research was funded by Skim Geran Penyelidikan Fundamental (FRGS) as part of the project of "Inverstigation of the direct and semidirect radiative effect of burning aerosols From AERONET and MPLNET data over Southeast Asian Maritime Continent"

No. Akaun : 203 / PFIZIK / 6711608.

\section{References}

[1] Cadet, J., \& Douki, T. (2018). Formation of UV-induced DNA damage contributing to skin cancer development. Photochemical \& Photobiological Sciences.

[2] Chakwizira, E., Teixeira, E., Meenken, E., Michel, A. J., \& Maley, S. (2018). Radiation use efficiency and biomass partitioning to storage roots in fodder beet crops. European Journal of Agronomy, 92, 63-71.

[3] Coddington, O., Lean, J.L., Pilewskie, P., Snow, M. and Lindholm, D., 2016. A solar irradiance climate data record. Bulletin of the American Meteorological Society, 97(7), pp.1265-1282.

[4] Demain, C., Journée, M., \& Bertrand, C. (2013). Evaluation of different models to estimate the global solar radiation on inclined surfaces. Renewable Energy, 50, 710-721.

[5] Diagne, M., David, M., Lauret, P., Boland, J., \& Schmutz, N. (2013). Review of solar irradiance forecasting methods and a proposition for small-scale insular grids. Renewable and Sustainable Energy Reviews, 27, 65-76.

[6] Eltbaakh, Y. A., Ruslan, M. H., Alghoul, M. A., Othman, M. Y., Sopian, K., \& Fadhel, M. I. (2011). Measurement of total and spectral solar irradiance: Overview of existing research. Renewable and Sustainable Energy Reviews, 15(3), 1403-1426.

[7] Eltbaakh, Y.A., Ruslan, M.H., Alghoul, M.A., Othman, M.Y. and Sopian, K., 2013. Measurements of spectral-band solar irradiance in Bangi, Malaysia. Solar Energy, 89, pp.62-80.

[8] Ineichen, P. (2016). Validation of models that estimate the clear sky global and beam solar irradiance. Solar Energy, 132, 332-344.

[9] Islam, M.D., Kubo, I., Ohadi, M. and Alili, A.A., 2009. Measurement of solar energy radiation in Abu Dhabi, UAE. Applied Energy, 86(4), pp.511-515.

[10] Jacovides, C.P., Steven, M.D. and Asimakopoulos, D.N., 2000. Solar spectral irradiance under clear skies around a major metropolitan area. Journal of Applied Meteorology, 39(6), pp.917-930.

[11] Jimenez-Munoz, J.C.; Sobrino, J.A.; Mattar, C.; Franch, B. Atmospheric correction of optical imagery from MODIS and reanalysis atmospheric products. Remote Sens. Environ. 2010, 114, 2195 2210

[12] Jompob Waewsak, 2004, The Spectral Transmittance due to Water Vapor, Ozone and Aerosol of Cloudless Atmosphere over the Central Part of Thailand. Thammasat Int. J.Sc. Tech., Vol.9, No. 3, July-September 2004.

[13] Kastendeuch, P.P. A method to estimate sky view factors from digital elevation models. Int. J. Climatol. 2013, 33, 1574-1578.

[14] Kim, C. K., \& Clarkson, M. (2016). Toward improved solar irradiance forecasts: introduction of post-processing to correct the direct normal irradiance from the weather research and forecasting model. Pure and Applied Geophysics, 173(5), 1751-1763.

[15] Kopp, G. and Lean, J.L., 2011. A new, lower value of total solar irradiance: Evidence and climate significance. Geophysical Research Letters, 38(1).

[16] Kopp, G. and Lean, J.L., 2011. A new, lower value of total solar irradiance: Evidence and climate significance. Geophysical Research Letters, 38(1).

[17] Liew, S.C., Tan, W.J. and Kwoh, L.K., 2017, July. Post-launch radiometric calibration of TeLEOS-1 satellite imaging sensor. In $G e$ oscience and Remote Sensing Symposium (IGARSS), 2017 IEEE International (pp. 4692-4694). IEEE

[18] Li, D. H., Lou, S., Lam, J. C., \& Wu, R. H. (2016). Determining solar irradiance on inclined planes from classified CIE (International Commission on Illumination) standard skies. Energy, 101, 462470.

[19] Li P, Shi C, Li Z, Muller JP, Drummond J, Li X, Li T, Li Y, Liu J. Evaluation of ASTER GDEM using GPS benchmarks and SRTM in China. Int. J. Remote Sens. 2013, 34, 1744-1771

[20] Liu, Y., Shimada, S., Yoshino, J., Kobayashi, T., Miwa, Y., \& Furuta, K. (2016). Ensemble forecasting of solar irradiance by ap- plying a mesoscale meteorological model. Solar Energy, 136, 597 605 .

[21] Murshed, S. M., Simons, A., Lindsay, A., Picard, S., \& De Pin, C. (2018, March). Evaluation of two solar radiation algorithms on 3D city models for calculating photovoltaic potential. In 4th international conference on geographical information systems theory, applications and management (pp. 17-19).

[22] Roman, M.O, Gatebe CK, Schaaf CB, Poudyal R, Wang Z, King MD. Variability in surface BRDF at different spatial scales $(30 \mathrm{~m}-$ $500 \mathrm{~m}$ ) over a mixed agricultural landscape as retrieved from airborne and satellite spectral measurements. Remote Sens. Environ. 2011, 115, 2184-2203

[23] Szantoi, Z.; Simonetti, D. Fast and robust topographic correction method for medium resolution satellite imagery using a stratified approach. IEEE J. Sel. Top. Appl. Earth Obs. Remote Sens. 2013, 6 , 1921-1933.

[24] Vanonckelen, S.; Lhermitte, S.; Rompaey, A.V. The effect of atmospheric and topographic correction methods on land cover classification accuracy. Int. J.Appl. Earth. Obs. 2013, 24, 9-21.

[25] Yadav, A. K., \& Chandel, S. S. (2014). Solar radiation prediction using Artificial Neural Network techniques: A review. Renewable and sustainable energy reviews, 33, 772-781.

[26] Zaksek, K.; Ostir, K.; Kokalj, Z. Sky-view factor as a relief visualization technique. Remote Sens. 2011, 3, 398-415. 